\title{
PESQ UISA QUALITATIVA, ENSINO E ASSISTÊNCIA DE ENFERMAGEM: INTERAÇÃO QUE FAVORECE O CUIDADO CULTURAL
}

\author{
QUALITATIVE RESEARCH, TEACHING AND NURSING CARE: THE \\ INTERACTION TO FACILITATE THE CULTURAL CARE \\ INVESTIGACIÓN CUALITATIVA, EN SEÑ ANZA Y ASISTENCIA DE \\ ENFERMERÍA: INTERACCIÓN QUE FAVORECE EL CUIDADO CULTURAL \\ NEIDE DE SOUZA PRAÇA*
}

\begin{abstract}
RESUMO
Este texto tem como objetivo mostrar a contribuição da tríade ensino, assistência de enfermagem e pesquisa qualitativa na identificação de dados que direcionam o cuidado cultural às mulheres moradoras em uma favela da cidade de São Paulo, Brasil. Apresenta a trajetória da pesquisadora desde sua inserção na comunidade prestando assistência de enfermagem obstétrica e realizando ensino de alunos de graduação em enfermagem até a conclusão desua pesquisa, da qual apresenta o grupo cultural. A pesquisa que teve a antropologia cultural como referencial teórico e a etnografia como método colaborou na definição do cuidado culturalmente embasado às mulheres assistidas/ estudadas.
\end{abstract}

Palavras chaves: Assistência de enfermagem, ensino, etnografia.

\begin{abstract}
ABST RACT
Theaim of this text isto show the contribution of the tread: teaching nursing care and qualitative research in the identification of data related the cultural care of women living in a slum in the city of São Paulo, Brazil. This text also shows the steps of the researcher beginning with her insertion in the community giving obstetric nursing care to the women and teaching undergraduate students. The research was a qualitativestudy theoretically based on cultural anthropology and on ethnographic methodology. The results show the cultural group care conceptualization and allow a reflection of the cultural nursing care of those women.
\end{abstract}

Keywords: Nursing care, instructions, etnography.

\section{RESUMEN}

Este texto tiene como objetivo mostrar la contribución de la tríada enseñanza, cuidado de enfermería e investigación cualitativa en la identificación de información que se relaciona con el cuidado cultural en mujeres habitantes de un asentamiento urbano marginal de la ciudad de São Paulo, Brasil. Presenta la trayectoria de la investigadora desdesu inserción en la comunidad prestando cuidado de enfermería obstétrica y desempeñando docencia con alumnos de pregrado en enfermería, hasta la conclusión desu investigación, dela cual presenta el grupo cultural. La investigación, que tuvo a la antropología como referencial teórico y a la etnografía como método, permitió definir el cuidado con una fundamento cultural en estas mujeres cuidadas/estudiadas.

Palabras claves: Asistencia de enfermería, enseñanza, etnografía.

Recepcionado: 15.10.2001. Aceptado: 19.07.2003.

*Enfermeira Obstétrica. Professor Doutor do D epartamento de Enfermagem M aterno-Infantil e Psiquiátrica da Escola de Enfermagem da Universidade de São Paulo. São Paulo, Brasil. Av. Dr. Enéas de Carvalho Aguiar, 419 CEP 05403-000 São Paulo, SP, Brasil. E-mail: ndspraca@usp.br 


\section{INTRODUÇÃO}

A tríade ensino, pesquisa e extensão constitui-se no pilar que norteia as atividades da universidade. Deseus docentes éesperado que se dediquem a cada uma destas funções.

Com esta proposta, o compromisso da universidade para com a sociedade reverte-se sob a forma de prestação de serviços realizada pelos seus docentes e alunos, o que gera vínculo entre a universidade ea comunidade.

Sousa (1998) afirma quea extensão deserviços à comunidade tem como papel histórico "aproximar a universidade da sociedade". Para esta autora, com a qual concordamos, a universidade se constitui em uma "instituição educativa e/ou transformadora", cujo papel é "abrir o horizonte intelectual do estudante, colocando conteúdos que tornem a educação um instrumento não só para a vida, mas para a transformação da vida e da sociedade". A extensão é facilitadora do alcance deste objetivo.

Esta atividade pertinente à função docente, realizada em conjunto com o ensino de graduação em enfermagem, gerou o desenvolvimento de uma pesquisa qualitativa que tevea etnografia como referencial metodológico. As participantes do estudo foram as clientes atendidas durantea atividade de extensão. 0 relato desta experiência de integração entrea assi stência à comunidade, 0 ensino ea pesquisa constituem o conteúdo deste texto.

Este texto tem como objetivo mostrar a contribuição da tríade ensino, assistência de enfermagem e pesquisa para a identificação de dados que direcionem o cuidado cultural a ser prestado a mulheres moradoras em uma favela do Município deSão Paulo, Brasil.

\section{ASSISTÊNCIA PRESTADA}

No período de março de 1994 a dezembro de 1997 as docentes da disciplina Enfermagem na Saúde da Mulher da Escola de Enfermagem daUniversidade deSão Paulo realizaram atividades docente-assistenciais em uma favela localizada na Zona O este do Município de São Paulo.

A favela, constituída por aproximadamente 3.000 famílias, subdivide-se em cinco comunidades. Nosso trabalho foi realizado na comunidade localizada na área de abrangência de um centro comunitário mantido por uma congregação católica.

Neste centro comunitário, localizado no interior da área física da favela, os alunos do curso de graduação em enfermagem e as docentes realizavam consulta pré natal às gestantes de baixo risco e visita domiciliária ao binômio mãe-recém-nascido. Estas tarefas eram compartilhadas entre três docentes da disciplina, sendo eu uma delas.

Esse trabalho resultou da aceitação de um convitefeito pela congregação que coordenava as atividades do centro comunitário e foi motivado pela dificuldade apresentada pelas mulheres residentes na favela em obter assistência prénnatal na unidade básica de saúde de referência da região. A remodelação do currículo do curso degraduação da Escola de Enfermagem da Universidade de São Paulo e a conseqüente necessidade de abertura de novos horizontes para o ensino da disciplina Enfermagem na Saúde da Mulher levoram a aceitar o referido convite visualizando a possibilidadedeinvestir nacomunidadeem questão.

Nossa atuação na comunidade como enfermeiras obstétricas e docentes de enfermagem iniciou-se com atividades de extensão. Introduzimosum programa deassistência de enfermagem à mulher no ciclo grávidopuerperal, incluindo o recém-nascido, ambos vistos e assistidos sob o prisma do contexto social no qual estavam inseridos, modelo que ia além de nossa experiência profissional, até então voltada à assistência obstétrica institucional. Após a consolidação deste trabalho, passamosa levar os alunos degraduação para o ensino teórico-prático no local. Estes alunos cursavam o terceiro, o quarto, o quinto ou o sexto semestre do curso de enfermagem. 
Desenvolvemos nosso trabalho tendo como alvo estender as ações de saúde às gestantes da região abrangida pela comunidade, bem como contribuir para a diminuição da morbi-mortalidadeperinatal identificando as causas preveníveis e controláveis durante 0 atendimento pré e pós-natal.

As atividades de assistência às mulheres eram realizadas nas dependências do centro comunitário onde, sob nossa orientação, foi organizado um espaço físico que possibilitava 0 atendimento simultâneo de três mulheres e de um recém-nascido.

A articulação entre nosso serviço, a unidade básica de saúde e o hospital universitário (HU-USP) foi aos pou cos sendo sedimentada e estas unidades passaram a nos dar retaguarda médica, realizar exames e tratamentos quando os solicitávamos.

Nossas atividades serão sucintamentedescritas a seguir, com realce para a trajetória por mim seguida, enquanto pesquisadora.

\section{Prénatal}

A assistência pré natal era efetuada três vezes por semana, no horário da manhã, com agendamento de 10 consultas diárias. Era realizada pelas docentes e pelos alunos, estes durante o período letivo. As consultas constavam de anamnese e verificação de peso e estatura da gestante, exame físico e obstétri$c 0$, encaminhamentos para exames laboratoriais de rotina pré-natal e para tratamentos se necessário. Constavam ainda orientação individual e encaminhamento ao hospital de referência para ultrassonografia obstétrica e para tratamentos e/ou internação.

Cabe destacar que 0 atendimento de cada gestante em consulta realizada por mim ou pelo aluno, sob minha supervisão, possibilitou-me conhecer einteragir com cada gestante, 0 que se tornou altamente gratificante. $M$ inha constante presença junto à clientela possibilitou ainda meu entrosamento com os demais atores do contexto. Ao atender as ges- tantes em consultas subseqüentes de pré-natal ao longo da gravidez, meu contato com cada uma delas estreitava-seà medida em que se aproximava a data do parto. Estefato favoreceu minha interação com as informantes selecionadas para a futura pesquisa.

\section{Consulta de enfermagem}

Num trabalho contínuo de assistência às mulheres grávidas, esten demos nossa atuação à mãe e ao recém-nascido após o parto. Realizávamos a consulta de enfermagem à puérpera e ao recém-nascido com a finalidade de avaliar a evolução deambos, aproximadamente vinte ou 30 dias de pós-parto.

A consulta mãe/ filho complementavanossos dados sobrea evolução da gravidez econtribuía para fornecer uma visão global do binômio e de sua família.

Essa consulta se constituiu em satisfação profissional para as docentes e também para os alunos que resaltaram a oportunidade de vivenciar as medidas de atenção à saúde em nível primário no decorrer da assistência.

\section{Visita domiciliária}

As gestantes que não compareciam à consulta de pré natal, bem como as puérperas que apresentavam problemas médico-sociais, de tectados na consulta de retorno, ou que tiveram recém-nascidos prematuros ou com intercorrências e binômios que não compareciam à consulta de retorno agendada recebiam visita domiciliária, realizada pela enfermeira-docente e/ou alunos. Seu objetivo era avaliar e atender as necessidades de mãe e fiIho. Nesta ocasião era comum detectarmos intercorrências de saúde de outros membros da família da gestante/puérpera, cujos encaminhamentos eram por nós efetuados, de acordo com as possibilidades do serviço.

0 fato das mulheres que atendíamos na comunidade residirem nas proximidades do 
centro comunitário onde atuávamos facilitava nossa ida a suas casas, possibilitando, assim, prestar-Ihes assistência à saúde. As visitas domiciliárias mostraram-se como atividades de grande valor no aprendizado dos alunos sobre o contexto social em que ocorria o cuidado.

A localização da casa de cada cliente que pertencia à área de abrangência do centro comunitário, ser recebida cordialmente pelas mulheres esuas famílias em suas casas durante as visitas domiciliárias, ser reconhecida quando caminhava pela favela emanter contato individual em cada consulta a que a mulher se submetia contribuíram também para a minha inserção na comunidade. Tal aproximação facilitou-me, posteriormente, resgatar, em suas próprias casas, algumas mulheres que se tornariam informantes do estudo que planejava.

Os alunos avaliaram as visitas domiciliárias no decorrer e ao final do processo ensinoaprendizagem. Sua avaliação mostrou que as visitas domiciliárias foram importantes para a incorporação das diferenças existentes entre os pontos de vista do aluno/profissional e da clientela, no queconcerneànecessidadedesaúde, cuidado eatendimento às suas demandas. Além disso, constituíram-se em situações ímpares que levaram docentes e alunos envolvidos a refletir e rever seus valores pessoais e, conseqüentemente, a forma de visualizar o outro, em especial, as nossas clientes.

A avaliação realizada pelos alunos sobre suas atividades na comunidade, durante sua formação, foi apresentada no estudo qualitativo de Merighi, Bonadio (1998) realizado com 13 alunos que participaram do ensino no centro comunitário. Estas autoras verificaram como os alunos perceberam sua vivência durante 0 aprendizado teórico-prático. Os dados mostraram que os alunos consideraram a experiência como "gratificante, estimulante e valiosa"; discorrendo que foi "uma experiência de vida, de crescimento pessoal e de quebra de preconceito", que foi uma "atividade que permite conhecer o outro lado da assistência; uma atividade prática que possibilita sedimentação do conhecimento adquirido teoricamente; uma experiência importante e necessária".

\section{INTEGRANDO A PESQUISA AO ENSINO E À ASSISTÊNCIA}

A participação nas atividades assistenciais e de ensino despertou-me para o fato de que poderia realizar um estudo com o grupo cultural daquela comunidade. Passei a investir em uma pesquisa qualitativa que caminhasse paralelamente ao ensino dos alunos de graduação e à assistência às mulheres da comunidade onde me inserira.

Ao considerar os moradores da favela como um grupo culturalmente definido, a opção pela antropologia cultural como referencial teórico e pela etnografia como referencial metodológico atendeu ao objetivo delineado para o estudo que se constituiu em minha TesedeD outoramento (Praça, Gualda, 2000).

\section{Antropologia cultural}

A antropologia cultural, vista como norteadora dos comportamentos dos indivíduos, possibilitou-metrabalhar com o cognitivo das mulheres no seu cotidiano de enfrentamento a doenças.

N este aspecto, creio ser relevante destacar a posição de Bernardi (1974) que considera como elementos essenciais de uma cultura a comunidade (associação estruturada de pessoas), 0 ambiente no qual o homem se encontra, o tempo (momento em quea ação humana se desenvolve) e o homem enquanto indivíduo com seus valores. Esse autor refere quevalor équalquer elemento constitutivo da cultura, transmitido tradicionalmente, porém sujeito a modificações dependentes das relações humanas. Crêainda que o valor, quando integrado ao sistema, leva cada membro de 
uma dada sociedadee o seu conjunto a seguilo. Estas afirmações nos permitem considerar que a cultura embasa-se na ação individual e esta representa a coletividade.

Dentre várias definições de cultura encontradasnaliteratura, optei pela feita por Schwartz (1995) cujo significado melhor se aproximava do objetivo do estudo. Assim, a pesquisa teve como norte a afirmação desse autor ao dizer que "a cultura consiste nos derivativos da experiência, mais ou menos organizada, aprendida ou criada pelos indivíduos deuma população, incluindo eventos ou códigos e suas interpretações (significados) transmitidos de gerações passadas, de contemporâneos ou formadas pelos próprios indivíduos".

Como reforço a esta opção encontrei na afirmativa de Gualda (2002) a conceituação decultura sob abordagem cognitiva, que busca estudar as crenças, os val ores eos conhecimentos dos membros do grupo social sobre o tema a ser pesquisado.

Paral elamente, de acordo com Peacock (1997), na área médica, o olhar antropológico favorece a preocupação holística com a pessoa, que passa a ser vista no seu contexto sócio-cultural e não somente quanto ao aspecto bio-psicológico. Sua aplicação possibilitou-me melhor compreender a cultura dos moradores da comunidade onde prestava assistência como atividade de extensão e também realizava ensino teórico-prático.

\section{Etnografia}

Dada à natureza do estudo, optei pela etnografia para a coleta e análise dos dados. Passo a seguir a descrever a trajetória metodológica por mim realizada na obtenção e análise dos dados do citado estudo.

\section{Seguindo o método etnográfico}

Atuei na comunidade no período de agosto de 1995 a dezembro de 1996, realizando ensi- no de alunos de graduação e assistência de enfermagem às mulheres moradoras no local.

Ao freqüentar o centro comunitário, semanalmente, foi possível aos residentes da comunidadeidentificarem a mim eao grupo de docentes que prestavam assistência como "as professoras da USP que fazem o pré-natal" e passassem a ver-nos como elementos de presença rotineira, deixando de ser estranhos a eles. Realizava-se, assim, minha inserção naquele campo.

Acompanhar os alunos em visita domiciliária, procurando as residências a partir do endereço fornecido pela gestante e transitar pelas vielas e becos da favela facilitaram-me melhor conhecer sua estrutura eorganização, bem como identificar as características deseus moradores e ser identificada por eles.

Num processo dinâmico, iniciei o registro dedados no diário de campo, ao mesmo tempo em que realizava a observação participante do contexto ea minha atuação docenteassistencial na comunidade: diariamente, ao concluir minhas atividades de assistência e de ensino programadas, anotava num caderno minhas observações, percepção sobrefatos, sentimentose dificuldades vivenciadas durante a realização das tarefas profissionais e observação do contexto. Estes dados contribuíram para enriquecer minha análise sobre aquelegrupo cultural.

Para a seleção dos sujeitos do estudo, primeiramente, desenhei uma amostra representativa demulheres para as quais eu havia prestado assistência pré-natal. Para tal, utilizando o prontuário médico de cada gestante, selecionei, num primeiro momento, as mulheres que viviam em estado marital, que residiam na comunidade há mais de um ano eque vivenciavam o primeiro ou segundo trimestre de gravidez. Posteriormente, com o progresso da pesquisa, selecionei, dentre as primeiras, as mulheres que demonstravam facilidade de expressão ao discorrer livremente sobre temas diversos, apresentando clareza, coerência e seqüência lógica de pensamento. Não 
houvedeterminação do número deinformantes neste momento.

No princípio de 1997 encerrou-se o trabaIho por nós realizado no centro comunitário devido a mudanças na política de saúde do município, impossibilitando o trabalho conjunto entrenosso serviço, a unidadebásica de saúde e o HU-USP, referências e retaguarda médica para 0 atendimento de nossa clientela. Durante o período em que funcionou, 0 serviço atendeu 282 gestantes, moradoras na comunidade, as quais mostraram-se satisfeitas com a assistência recebida, fato expresso informalmenteem reuniões com os líderes da comunidade e da congregação religiosa que nos havia convidado.

Como conseqüência do encerramento das atividades, a partir de janeiro de 1997 passei a comparecer à favela apenas para coletar os dados para concluir a pesquisajáiniciada com minha inserção na comunidade e com algumas entrevistas. Na ocasião, contatava as muIheres, ex-clientes, para entrevistá-las em suas casas ou nas dependên cias do centro comunitário, quando elas optavam por esse local.

Dentre as mulheres previamente selecionadas, seis constituíram-se nas sujeitos do estudo. Eram moradoras da comunidade às quais prestei assistência pré-natal realizando consulta, orientação individual sobre cuidados com a gravidez, parto, puerpério, com o recém-nascido e visita domiciliária. As entrevistas se realizaram no período de setembro de 1996 a abril de 1998.

Todas as mulheres por mim contatadas aceitaram participar do estudo, demonstrando interesse e satisfação por colaborar, sendo informadas na ocasião sobrea garantia deseu anonimato e a possibilidade de recusar-se a participar, seassim preferissem. Vale acrescentar que a coleta de dados iniciou-se anteriormente à criação, no Brasil, dos Comitês de Ética em Pesquisa, motivo pelo qual este estudo teve aprovação deuma Comissão deEspecialistas em Pesquisa e não de um Comitê de Ética.

A maioria das entrevistas ocorreu na casa das informantes eforam realizadas por mim, assim como a sua transcrição eanálise do conteúdo. Esteprocedimento possibilitou-mereflexão, avaliação e validação dos resultados. Todas as entrevistas foram gravadas em fitas magnéticas, posteriormente transcritas e digitadas. Cada informante deu uma ou duas entrevistas ao longo do estudo.

0 período de entrevistas caracterizou-se por idas e vindas à comunidade, ten do inclusive parte dele coincidido com a extinção das atividades de assistência prénatal até então desenvolvidas no centro comunitário.

Para complementar os dados dasinformantes, utilizei a pesquisa suplementar de dados, analisando os registros feitos nos prontuários individuais das gestantes atendidas no centro comunitário, utilizadosduranteas consultas de pré-natal. Esta pesquisa ajudou-mea caracterizar cada uma das informantes do estudo, bem como forneceu-me subsídios sobre todas as mulheres atendidas, dando-me a idéia do coletivo das famílias daquele grupo cultural.

O utra estratégia que empreguei durante a coleta de dadosfoi fotografar o contexto, o que também subsidiou o desenho do cenário cultural.

Conforme citado anteriormente, realizei esteestudo norteada pel o método etnográfico, efetuando as fases de coleta e de análise de dados simultaneamente.

O conteúdo decada entrevista, após transcrição, foi digitado acrescido dos dados pessoais de cada informante obtidos durante a entrevista ou pela leitura de seus prontuários médicos. As características de sua resi dência, observadas durantea visita domiciliária, também foram registradas neste momento.

Os resultados obtidos emergiram dos relatos das informantes e também dos dados verificados com a observação participante e com a análise documental, ambas realizadas durante o trabalho de campo.

Para a análise dos dados obtidos segui 0 método proposto por Hammersley, Atkinson (1990) segundo o qual, primeiramente, foram extraídos os conceitos sensibilizantes conti- 
dos nas falas de cada entrevistada, os quais, num segundo momento, tornaram-se, ou não, conceitos definitivos. Estes são identificados como algo que se destaque como surpreendente ou intrigante ao pesquisador, com base nos relatos a partir do conhecimento do senso comum, de relatos oficiais ou de teoria anterior. 0 passo seguinte foi o agrupamento por afinidadedos relatos que compõem cada conceito definitivo, originando as categorias analíticas. Com o agrupamento das categorias semelhantes obtiveas tipologias que representam sub-tipos de uma categoria mais geral (tema). Neste estudo encontrei como tipologias, os sub-temas "cuidando da saúde da família", "constituindo afamília" e"homem trazendo a AIDS para dentro de casa". A análise do conteúdo destes sub-temas levou-me ao tema "a cuidadora e o (ser)cuidado: uma relação de dependência no enfrentamento da AIDS".

A validação dos dados obtidos foi feita pelasinformantes entrevistadas apóso início da análise dos primeiros dados. Ao realizar a segunda entrevista, apresentava à mulher a interpretação que fizera sobre os dados de todas as entrevistas até então analisadas. Sua concordância melevou a considerar os dados validados.

\section{APRESENTAND 0 O GRUPO CULTURAL}

A trajetória por mim percorrida desdeminha inserção na comunidade prestando assistência de enfermagem obstétrica às mulheres $e$ realizando ensino dosal unos degraduação em enfermagem foi favorecida também pela prática dos passos metodológicos indicados para a pesquisa realizada, segundo o método adotado. A conjunção destes fatores permitiu-me conhecer as crenças e os val ores dos moradores da comunidade, com enfoque para a relação saúde doença, o que permite traçar sua assistência com base no cuidado cultural.

Cabe ressaltar que a exploração de culturas dentro do paradigma da Enfermagem é facilitada pela posição do enfermeiro pesquisador no cenário cultural, pois, ao valorizar a natureza cognitiva do ser humano, tem a possibilidadedemelhor compreender a dinâmica do fenômeno sob estudo e os relacionamentos presentes na cultura. Esta compreensão auxilia o enfermeiro a prestar cuidado culturalmente embasado e, portanto, proceder a intervenções mais adequadas à sua clientela (Streubert, Carpenter, 1995).

Por suavez, Tripp-Reimer, Brink, Saunders (1984) referem que o conhecimento da cultura da clientela, pelo enfermeiro, Ihe proporciona melhor entender o comportamento ea maneira como o cliente percebea situação de saúdee ou de doença. A avaliação cultural faz aflorar as crenças, os valores e os costumes compartilhados pelos atores sociais e que direcionam seu comportamento em relação à saúde.

Creio ser relevante apresentar brevemente o grupo cultural estudado, conhecimento obtido com a integração entre os resultados da pesquisa, a assistência prestada às mulheres da comunidade e o ensino de graduação realizado no local.

Neste grupo cultural, as famílias são constituídas pela união consensual de um casal formado, geralmente, pela mulher adolescente, ou recém saída da adolescência, epelo homem com maisidade. A família assi m constituída tendea residir em casa separada de seus familiares, embora próxima a eles.

O princípio de uma vida em comum é marcado pela construção deum pequeno barraco em qualquer espaço de terreno disponível, mobiliado precariamente. Com o passar do tempo e com o trabalho do homem, estes barracos são modificados. A busca pela me Ihora da apresentação estética das casas é constante e envolve seu morador nas reformas. A precariedade das moradias e 0 tamanho reduzido da maioria delas, no entanto, não impedem que as famílias possuam aparelhos de TV, rádio emobiliário conservado.

As mulheres apresentam como fontes de diversão, os programas de televisão, as con- 
versas na casa de amigos, as freqüentes visitas aosfamiliares, especialmenteà mãe, e o comparecimento esporádico àmissa católica. Seus parceiros, em geral, trabalham durante o dia e, nas horas de descanso, costumam reunirse com amigos em um dos vários bares em funcionamento na comunidade. São raras as saídas do casal parafreqüentar ambientes fora da favela.

A maioria dos casais tem escolaridade até o primeiro grau incompleto, ou são analfabetos. Raros são os indivíduos com o segundo grau completo. Neste grupo cultural, a muIher responde pelo cuidado da casa e dos fiIhos, enquanto seu companheiro mantém o sustento da família.

Uma vez preocupada com os cuidados da casa e com o bem-estar dos filhos, éa mulher quem busca tratamento quando algum deles ou um de seus familiares, já adulto, adoece. Cabe a ela providenciar assistência, primeiramenteutilizando remédios caseiros ou medicamentosutilizados em situações semelhantes vividas anteriormente. Se, após empregar estas práticas, não notar modificação do quadro de doença apresentado ou se considerar quea intercorrênciaémais grave do queimaginava, a mulher busca, então, atendimento médico. Dá preferência ao pronto socorro ou hospital por disporem de maiores recursos para atendimento de urgência.

Se o indivíduo que adoece é um adulto, a mulher insiste para que procure atendimento médico, não sem antes fazer uso de práticas caseiras. Estas, em sua maioria, foram aprendidas com a mãe ou com a vizinha de mais idade, demonstrando a herança cultural que se perpetua pelas gerações.

Enquanto se preocupa com a saúde de familiares e dos filhos, a mulher delega a manutenção de sua própria saúdea um plano inferior de prioridades. Submete-se a exames somente durante o período pré-natal e são raras as mulheres que procuram o serviço de saúde para consulta periódica. Se o fazem é para submeter-seà citologia oncológica. Despreocupam-se, assim, com a própria saúde, enquanto mantêm-se atentas à saúde dos fiIhos e dos familiares.

\section{CONCLUSÃO}

Como podemos verificar, os dados culturais que emergiram da pesquisa com suporte de atividades de ensino edeassistência à mulher residente em uma comunidade favelar, mostraram que, neste grupo cultural, a mulher é a cuidadora da família e não tem como prioridade cuidar de sua própria saúde. Este fato nos aponta para a necessidade de implantação de programas que a auxiliem a manter a saúde dos filhos. Medidas preventivas e de higiene, de nutrição e de cuidados diante de uma situação de agravo à saúde devem ser enfocadas para que as mulheres possam realizar sua tarefa com segurança.

Estimular as mulheres submeterem-seperiodicamente ao exame de citologia oncológica e facilitar seu acesso aos serviços de saúdesão outras medidas relevantescomo cuidado embasado culturalmente.

N ossa experiência com o trabalho realizado mostrou-se gratificante porque possibilitou-nos melhor conhecer o grupo cultural constituído pelas mulheres e suas famílias, bem como por ter propiciado aos alunos modificar sua visão sobre a clientela.

Acreditamostambém quea implantação e a expansão dos Programas de Saúde da Família como política de saúde atual contribuirão para a melhoria da assistência oferecida à população residente em áreas onde 0 atendimento à saúde ainda é precário.

Concluindo, este texto mostrou a trajetória percorrida pelo cuidador, pesquisador e docente de enfermagem, ao realizar assistência, ensino e pesquisa qual itativa em uma comunidade favelar do M unicípio de São Paulo. Procurou mostrar as faces de integração de atividades que possibilitaram identificar lacunas na atenção à saúde da clientela e traçar planos para o cuidado de enfermagem culturalmente embasado. 


\section{REFERÊNCIAS BIBLIOGRÁFICAS}

BERNARDI, B. (1974). Introdução aos estudos etnoantropológicos. Lisboa, Portugal, Edições 70.

GUALDA, D. M.R. (2002). Eu conheço minhanatureza: a expressão cultural do parto. São Paulo Brasil, Ed. Maio.

HAM M ERSLEY, M ., ATKIN SO N, P. (1990). Ethnography: principles in practice. London, Inglanterra, Ed. Routledge.

M ERIGI, M. A. B.; BONADIO, I. C. (1998). A vivência de alunos de graduação em enfermagem na assistência à saúde da mulher em comunidade de baixa renda - uma abordagem fenomenológica. Revista da Escola deEnfermagem da USP 32 (2), 109-116.

PEACOCK, J. L. (1997). The anthropological lens: harsh light, soft focus. New York, E.U.A., Cambridge University Press.
PRAÇA, N. S., GUALDA, D. M . R. (2000). A cuidadora e o (ser)cuidado: uma relação de dependência no enfrentamento daAIDS. Revista Paulista de Enfermagem 19(1) 43-52.

SCHWARTZ, T. (1995). Anthropology and psychology: an unrequited relationship. In: Schwartz, T.; White, G. M.; Lutz, C. A. New directions in psychological anthropology. New York, E.U.A., Cambridge University Press, cap. 16, pp. 324-49.

SOUSA, A. L. L. (1998). Extensão universitária - compromisso social ou solidariedade? RevistaAdusp 14, 23-28.

STREUBERT, H. J., CARPENTER, D. R. (1995). Qualitative research in nursing: advancing the humanistic imperative. Philadelphia, E.U.A., Lippincott Press.

TRIPP-REIM ER, T., BRINK, P. J., SAUNDERS, J. M . (1984). Cultural assessment: content and process. Nursing Outlook 32 (2) 78-82. 